\title{
Treatment of multiple recessions with collagen matrix versus connective tissue: a randomized clinical trial
}

\author{
Rodrigo NAHAS(a) \\ Valéria GONDIM(a) \\ Cassio Volponi CARVALHO(a) \\ Luis Marcelo CALDERERO(a) \\ Ecinele Francisca ROSA(a) \\ Thaís SAKIYAMA ${ }^{(a)}$ \\ João Batista CÉSAR NETO(a) \\ Cláudio Mendes PANNUTI(a) \\ Giuseppe Alexandre ROMITO(a) \\ (a) Universidade de São Paulo - USP, School of \\ Dentistry, Department of Stomatology, São \\ Paulo, SP, Brazil.
}

Declaration of Interests: The authors certify that they have no commercial or associative interest that represents a conflict of interest in connection with the manuscript.

Corresponding Author:

Giuseppe Alexandre Romito

E-mail: garomito@usp.br

htrps://doi.org/10.1590/1807-3107bor-2019.vol33.0123

Submitted: August 4, 2019

Accepted for publication: October 1, 2019

Last revision: November 28, 2019

\begin{abstract}
The objective of this study was to determine whether collagen matrix $(\mathrm{CM})$ is an alternative to connective tissue graft technique (CTG) in the treatment of multiple gingival recessions (GR). The indication of $\mathrm{CM}$ for the treatment of multiple GR is not yet clear. More studies are needed to better understand this treatment modality, as an alternative to CTG. In this single-blind, split-mouth randomized clinical trial, fifteen patients with multiple Miller class I upper GR were selected and randomly assigned to control group (CTG) or test group (CM). Root coverage (RC) and patient-centered outcomes were evaluated at baseline and after 3, 6, and 12 months. A total of 82 GRs were treated. There was no significant difference regarding GR depth (GRD, primary outcome) between CTG $(0.5 \pm 0.9 \mathrm{~mm})$ and $\mathrm{CM}$ groups $(0.6 \pm 1.0 \mathrm{~mm})(\mathrm{p}=0.225)$. Percentage of $\mathrm{RC}$ was $82.14 \%$ in CTG and $77.7 \%$ in CM. Both groups demonstrated a gain in keratinized tissue width at 12 months $(p<0.05)$. Dentine hypersensitivity was effectively reduced in both groups. Postoperative pain was significantly higher in the CTG ( $p=0.001)$. Esthetic satisfaction was high for both groups, with no significant difference $(p>0.05)$ between groups. After 12 months, both surgical treatments were able to promote $\mathrm{RC}$, and GRD was similar in both CTG and CM groups.
\end{abstract}

Keywords: Gingival Recession; Connective Tissue; Surgical Flaps; Periodontal Diseases.

\section{Introduction}

The coronally advanced flap, with or without subepithelial connective tissue graft (CTG) or biomaterials, has shown good results in the treatment of localized Miller class I and II gingival recessions (GR) ${ }^{1,2}$ The technique demonstrates high predictability for complete root coverage (CRC), with gain in keratinized tissue (KT) thickness and width. ${ }^{3}$ CTG is considered the treatment of choice for upper anterior isolated GR and premolar GR. ${ }^{4}$ However, the treatment of multiple GRs remains a challenge because of the large surgical field, anatomical factors, ${ }^{5}$ and the limited amount of connective tissue in the donor area. Systematic reviews have concluded that CTG offers the best clinical results in the treatment of multiple Miller class I and II GR. ${ }^{6}$ Despite its benefits, CTG is associated with longer operative time, pain, and discomfort related to the donor area. $7,8,9$ Furthermore, removal of the graft may cause trans- and postoperative 
complications. ${ }^{7,8,10}$ These factors are exacerbated in the treatment of multiple GR cases and when the need for donor tissue is increased. For such reasons, alternative surgical techniques and materials have been suggested and compared with CTG. ${ }^{11}$

Xenogeneic collagen matrix (CM) (Mucograft $\left.{ }^{\circledR}\right)$ has been proposed as a possible substitute for soft tissue grafts to increase the KT band around teeth and implants ${ }^{7,12}$ during the treatment of localized ${ }^{13,14}$ and multiple ${ }^{15,16} \mathrm{GR}$. Moreover, its use is associated with less pain and shorter operative time, as it does not depend on a donor site. ${ }^{11,14,16}$ A study that used $\mathrm{CM}$ to treat localized GR reported a percentage of root coverage (RC) of $75.29 \%$ after 6 months, ${ }^{13} 88.5 \%$ after 12 months, ${ }^{8}$ and $77.6 \%$ after 5 years. ${ }^{14}$ Another study on multiple GR using CM found RC percentage of $93.25 \%$ after 12 months. ${ }^{15}$

A multicenter trial on the treatment of localized GR indicated that CM combined with coronally advanced flap (CAF) resulted in $76.28 \%$ of $\mathrm{RC}$, a significant increase in KT width and gingival thickness, and significantly better patient-centered outcomes compared to CAF alone. ${ }^{17}$ Similarly, a more recent multicenter trial on treatment of multiple GRs provide strong evidence that the combination of a CM plus CAF results in shorter surgical time, shorter time to recovery, and better patient perception compared to CTG. ${ }^{16}$ On the other hand, this trial failed to support the non-inferiority hypothesis of CM compared with CTG in terms of root coverage after 6 months. ${ }^{16}$ Thus, the available data are limited, and more studies are needed to better understand this treatment modality.

We, therefore, conducted a randomized clinical trial with a split-mouth design to evaluate $\mathrm{CM}$ as an alternative to CTG to the treatment of multiple GRs after 12 months. The choice of this study design was based on a) the expectation that the difference in efficiency between CM and CTG would be clinically irrelevant in relation to $\mathrm{RC}$ and $\mathrm{b}$ ) that $\mathrm{CM}$ offers advantages over CTG in terms of postoperative pain and discomfort.

\section{Methodology}

\section{Study design}

This was a single-blind, randomized clinical trial with a split-mouth design (clinicaltrial.gov registration
NCT02818855). The study was based on the Consolidated Standards of Reporting Trials (CONSORT). ${ }^{18}$

\section{Participant selection}

This study was conducted at the postgraduate clinic of the University of São Paulo School of Dentistry in accordance with the ethical principles of the Helsinki Declaration of 1975, revised in 2000 (IRB approval no. 401.807).

Fifteen patients with multiple bilateral Class I Miller GR requiring root coverage were included in this study following these eligibility criteria:

a. Inclusion criteria: (Figures 1a, b, c and d); $\geq 18$ years of age; periodontally and systemically healthy; with esthetic complaint and/or dentine hypersensitivity; whole-mouth visible plaque index $\leq 20 \%$; multiple bilateral Class I Miller GR, involving canines and premolars (a minimum of 2 and a maximum of 3 teeth) with at least one GR $\geq 3 \mathrm{~mm}$; a visible cementoenamel junction (CEJ) or presence of slight root abrasion, but with an identifiable CEJ; ${ }^{9}$ at least 1 mm width of KT apical to the GR.

b. Exclusion criteria: Smokers and pregnant or lactating women; teeth with root caries, cervical lesions or cervical restoration; extruded, rotated, proclined or mobile teeth; history of surgery; systemic disease or the use of drugs that affect the periodontal tissue or healing.

\section{Interventions}

All the participants underwent crown/root scaling and professional plaque removal, and received oral hygiene instructions with a standardized extra-soft toothbrush. Surgical treatment was performed when the patient showed an adequate toothbrushing habit and the ability to control supragingival biofilm (overall Plaque Index $<20 \%$ ). All surgical procedures were performed by a single experienced surgeon (RN). In the control group, a modified coronally advanced flap (mCAF) was performed ${ }^{19}$ in association with a CTG removed from the palate using the double-blade technique ${ }^{20}$ with a distance of $1 \mathrm{~mm}$ between the blades. The final dimension of the graft was $1 \mathrm{~mm}$ in thickness and $10 \mathrm{~mm}$ in apico-coronal height. Regarding the mesio-distal dimension, the graft 


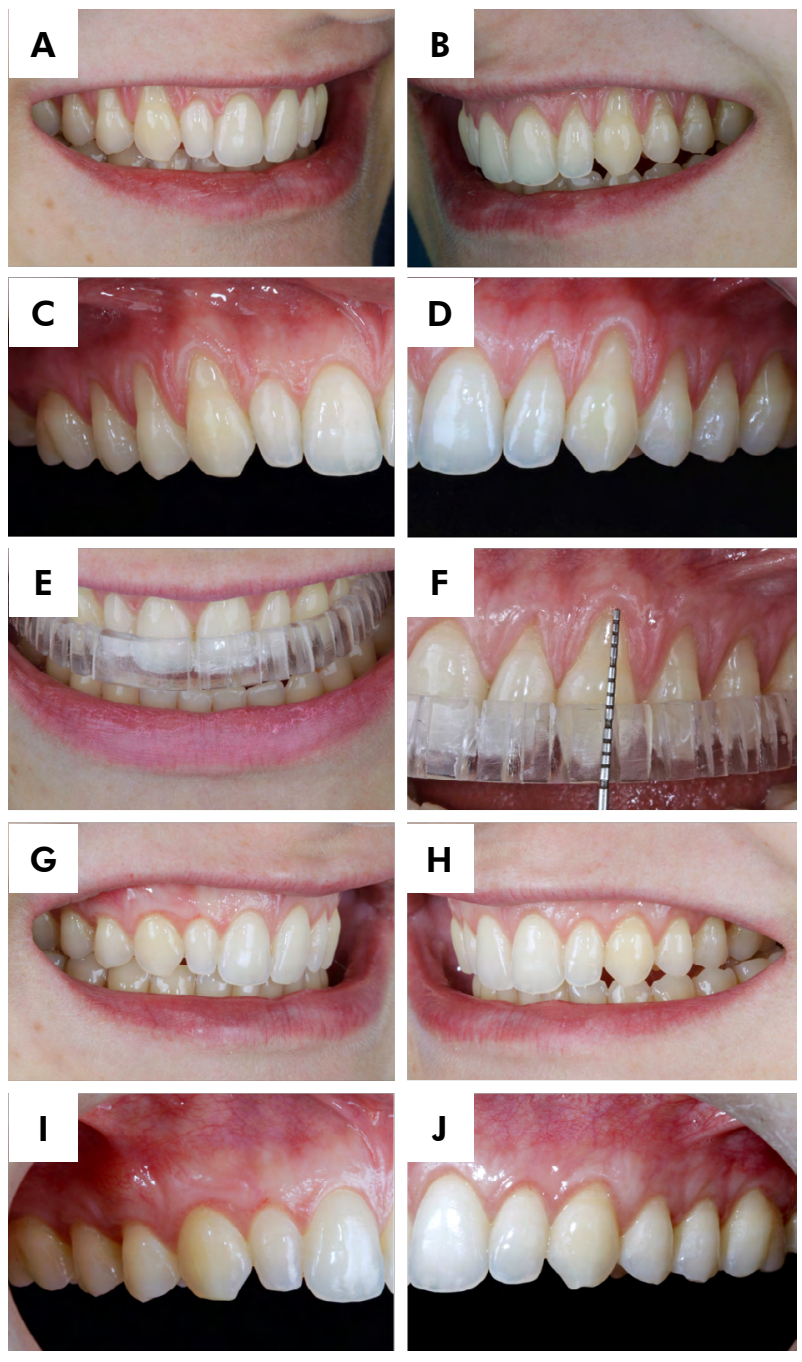

Figure 1. A. Initial appearance of the smile on the right side; B. Left side; C and D. Gingival recessions before surgical procedures; $\mathrm{E}$ and $\mathrm{F}$. The measurements were performed using a North Carolina probe (PCPUNC $15{ }^{\circledR} \mathrm{Hu}$ Friedy, Chicago, USA) and a standardized stent. Twelve months post-operative; $\mathrm{G}$. Final aspect of the smile on the right side; $H$. Left side; I. Root coverage with CTG treatment; J. Root coverage with CM treatment.

length extended $3 \mathrm{~mm}$ beyond the mesial aspect of the first tooth to be covered to $3 \mathrm{~mm}$ distal of the last tooth to be covered. All measurements of graft dimensions were checked by an expert periodontist using a North Carolina probe (PCPUNC $15^{\circledR} \mathrm{Hu}$ Friedy, Chicago, USA).

In the test group, the same mCAF was used but in association with the $\mathrm{CM}$. The $\mathrm{CM}$ was standardized with the same measures of the connective tissue graft but with the original thickness (3-6 mm).
Both grafts were placed in 2 or 3 teeth (only canines and premolars), depending on the number of recessions. In cases of recessions in canines, first and second premolars, the graft covered 3 teeth. In cases of recessions in canine and first premolar or first and second premolars, the graft covered 2 teeth.

Oblique submarginal incisions were made in the interdental areas, which continued with the intrasulcular incision at the GR. Split-full-split thickness flaps in the coronal-apical direction were elevated as follows: inter-dental surgical papillae (split-thickness), marginal soft tissue (full-thickness elevation of the buccal portion of the flap until the mucogingival junction, to provide a thicker flap for the most critical portion of root coverage), and the most apical portion of the flap (split-thickness to facilitate the coronal displacement of the flap). A periosteal incision was performed to eliminate muscle tension and allow the coronal advancement of the flap. Immediately after receptor site preparation, the opaque envelope with the randomization for the type of treatment was opened. CTG or CM was adapted and stabilized with sutures at the CEJ level on the exposed root surfaces. The flap was sutured $1 \mathrm{~mm}$ coronal to the CEJ with sling suture technique for multiple GR to allow a precise adaptation of the buccal flap and stabilize every single surgical papilla over the anatomical de-epithelialized papillae. Sutures were removed 15 days after the surgical treatment.

Post-operative pain and swelling were controlled with Nimesulide 2 times a day for 3 days. Patients were instructed not to brush their teeth in the treated area and gently rinse the mouth with $0.12 \%$ chlorhexidine gluconate solution 2 times a day ( $1 \mathrm{~min}$ ) for 2 weeks, and to consume only soft foods during those weeks. Patients returned to the clinic for prophylaxis and reinforcement of motivation and instruction for a non-traumatic tooth brushing technique 2 and 4 weeks after suture removal and subsequently every 3 months until the final examination (12 months).

The interval between the surgeries performed in the test and control groups did not exceed 2 months.

\section{Outcomes}

Primary outcome: gingival recession depth (GRD) (from the CEJ to the most apical point of the gingival margin) at 12 months. 
Secondary outcomes: bacterial plaque index, ${ }^{21}$ bleeding on probing (BP), probing depth (PD), clinical attachment level (CAL), and keratinized tissue width (KTW). ${ }^{22}$ Clinical parameters were recorded at baseline, 3, 6, and 12 months. Surgery time was also recorded.?

\section{Patient-related secondary outcomes}

a. Dentin hypersensitivity $(\mathrm{DH})$ was determined by the patient, using a $10-\mathrm{cm}$ visual analogic scale (VAS) after buccal surface stimulation of the treated teeth for 1 second at a distance of approximately $1 \mathrm{~cm}$ and with cotton roll isolation ${ }^{23}$, at baseline, 3, 6, and 12 months.

b. Postoperative pain and esthetics were based on the patient's subjective assessment using a 10-cm VAS ${ }^{8}$ and recorded by a single blinded evaluator (VG) at baseline, 7, 15, and 30 days, and 3, 6, and 12 months.

An esthetic assessment was also performed by a blinded periodontist (CVC) using the same protocol.

\section{Training and calibration}

Four training meetings were performed to standardize the selection of participants, measurements, and surgical procedures. Clinical measurements were taken by a single blinded evaluator (EFR) that was calibrated for the primary outcome (GRD). Calibration was based on evaluations of 4 patients not involved in the study performed at 7-day intervals. The intra-class correlation coefficient was 0.98 . The measurements were performed using a North Carolina probe (PCPUNC $15^{\circledR} \mathrm{Hu}$ Friedy, Chicago, USA) and a standardized stent (Figures le and $\mathrm{f})$.

\section{Randomization and allocation}

The experimental sites of participants were assigned to test (CM) or control (CTG) group using a software-generated random sequence (Random Allocation Software, Microsoft Visual Basic 6, Windows). Randomization was performed in blocks of 2 and 4, and participants were consecutively enrolled. During surgical procedure, immediately after preparation of the receptor site, the sequentially numbered opaque envelopes containing the type of treatment were opened.

\section{Sample size}

Sample size calculation was based on McGuire \& Scheyer's trial data. ${ }^{8}$ Considering an expected difference between groups of $0.4 \mathrm{~mm}$ for GRD, a $0.35 \mathrm{~mm}$ standard deviation, $80 \%$ power, and $5 \%$ alpha, 13 patients per group were required. Fifteen patients were finally included to compensate for possible dropouts.

\section{Data analysis}

Data analyses were divided in two series. In the first series, the outcomes were related to teeth with GR that underwent CM and CTG. The sample cluster characteristic was included in the analysis, as each participant underwent two surgical techniques and more than one tooth was included. Multilevel analyses were performed considering two levels: an evaluation of the teeth undergoing surgery (1st level), which were grouped according to the study participants (2nd level).

For statistical purposes, continuous variables that were measured in millimeters were treated as discrete variables. Poisson multilevel regression analyses were performed to compare their values at baseline between groups, and Kolmogorov-Smirnov test and Levene's test for equality of variances were performed for DH. Because the variable was consistent with at least one of the two assumptions, multilevel linear regression analyses were performed.

In the second series of analyses, periodontal parameters after different surgical techniques at different follow-up times were compared. Because there were 3 follow-up points after surgery $(3,6$, and 12 months), multilevel analyses were performed considering three levels: the evaluations at the different follow-up times (1st level) grouped according to the teeth undergoing surgery (2nd level), which, in turn, were grouped by study participant (3rd level).

Secondary outcomes were also calculated. These were again treated as discrete quantitative variables. Continuous outcome variables were compared using multilevel linear regression and categorical variables were analyzed using multilevel Poisson regression. Stata 13.0 (Stata Corp LP, College Station, USA) was used for all analyses with a significance level of $5 \%$. 
An ancillary analysis (subgroup analysis) of deep recessions ( $>4 \mathrm{~mm}$ ) was conducted in which groups were compared regarding GRD and change in GRD using Student's t-test.

\section{Results}

\section{Recruitment}

Fifteen participants -8 women (53.3\%) and 7 men $(46.7 \%)$ - with teeth sensitivity and/or an esthetic complaint were selected for this study. The mean age of participants was $32.7 \pm 8.1$ years (18-51 years). Patients were included from March 2014 to January 2015 (see study flowchart).

\section{Distribution of defects}

All participants completed the study and attended the follow-up appointments. A total of $82 \mathrm{GR}$ were treated ( 40 received CTG and 42 received CM) (Figure 2). All the participants had a low plaque index and bleeding on probing $(\leq 20 \%)$, with no significant difference between groups or among follow-up periods.

\section{Clinical parameters}

There was no significant difference between the groups at baseline for the variables GRD, PD, CAL, KTW, and DH (Table 1). There was no significant difference between groups for GRD 12 months after surgery $(p=0.225)$. The mean GRD of the CTG group was $2.8 \pm 1.1 \mathrm{~mm}$ at baseline and $0.5 \pm 0.9 \mathrm{~mm}$ after 12 months. In the cases treated with $\mathrm{CM}$, the mean GRD at baseline was $2.7 \pm 1.1 \mathrm{~mm}$ and the mean at 12 months was $0.6 \pm 1.0 \mathrm{~mm}$. The mean reduction in GR at 12 months was $2.2 \pm 1.2 \mathrm{~mm}$ for the control group and $2.0 \pm 1.2 \mathrm{~mm}$ for the test group $(\mathrm{p}=0.233)$. RC was $82.14 \%$ in the CTG group and $77.7 \%$ in CM. CRC was observed in $68 \%(n=27)$ of the treated sites in the control group and $60 \%(n=25)$ of the treated sites in the test group ( $p>0.05$; Table 2; Figures 1g, $h, i$, and $j)$.

There was no significant difference for PD and CAL gain between control and test groups at any time point ( $p>0.05$; Table 2 ). Both treatments resulted in significant gains in CAL at 3, 6, and 12 months $(p<0.05)$ (Table 2). At 12 months, the final mean KTW of the CTG group was significantly greater than that of CM group ( $p=0.022)$ (Table 2).

No difference between groups was detected for $\mathrm{DH}$ reductions at 12 months. After 12 months, there was a significant reduction in mean $\mathrm{DH}$ scores for both treatment groups $(\mathrm{p}<0.05)$, with no difference between groups (Table 3).

In both the CM group (9) and CTG group (7) recessions $>4 \mathrm{~mm}$ were observed. Due to the lack of evidence for the treatment of recessions $>4 \mathrm{~mm}$, a sub-analysis evaluating the performance of both therapies was performed. When only deep recessions where analyzed, CM presented greater mean GRD $(1.43 \pm 1.51 \mathrm{~mm})$ than CTG $(0.71 \pm 0.76 \mathrm{~mm})$ after 12 months. However, there was no significant difference between the two groups $(p=0.16)$. Furthermore, there was no significant difference $(p=0.09)$ between groups for change in recession depth $(\mathrm{CM}=2.57 \pm 1.51 \mathrm{~mm}$, CTG $=3.71 \pm 0.95 \mathrm{~mm}$ ).

\section{Operative time}

The mean operative time for the test group (31.3 \pm 4.3 minutes) was significantly lower than that for the control group $(47.7 \pm 6.1$ minutes $)(p<0.001)$.

No postoperative complications were observed. Both procedures generated postoperative pain at 8 hours, $1,7,15$, and 30 days $(\mathrm{p}<0.001)$. Postoperative pain was significantly higher in the CTG than in the $\mathrm{CM}$ at 8 hours, 7 and 15 days ( $\mathrm{p}<0.05)$. No significant difference between groups was observed after 30 days (Table 3).

\section{Esthetic evaluation}

Both patients and the specialist reported significant esthetic improvement in both groups after 12 months $(\mathrm{p}<0.05)$ with no significant difference between groups (Figures 1g, h, I, and j.; Figures 3 and 4).

\section{Discussion}

This is the first single-blinded, split-mouth randomized clinical trial to determine whether $\mathrm{CM}$ is an alternative to CTG for the treatment of multiple GR. This study was designed to compare CM in relation to CTG and the present data showed that CTG yielded similar results in terms of GRD 


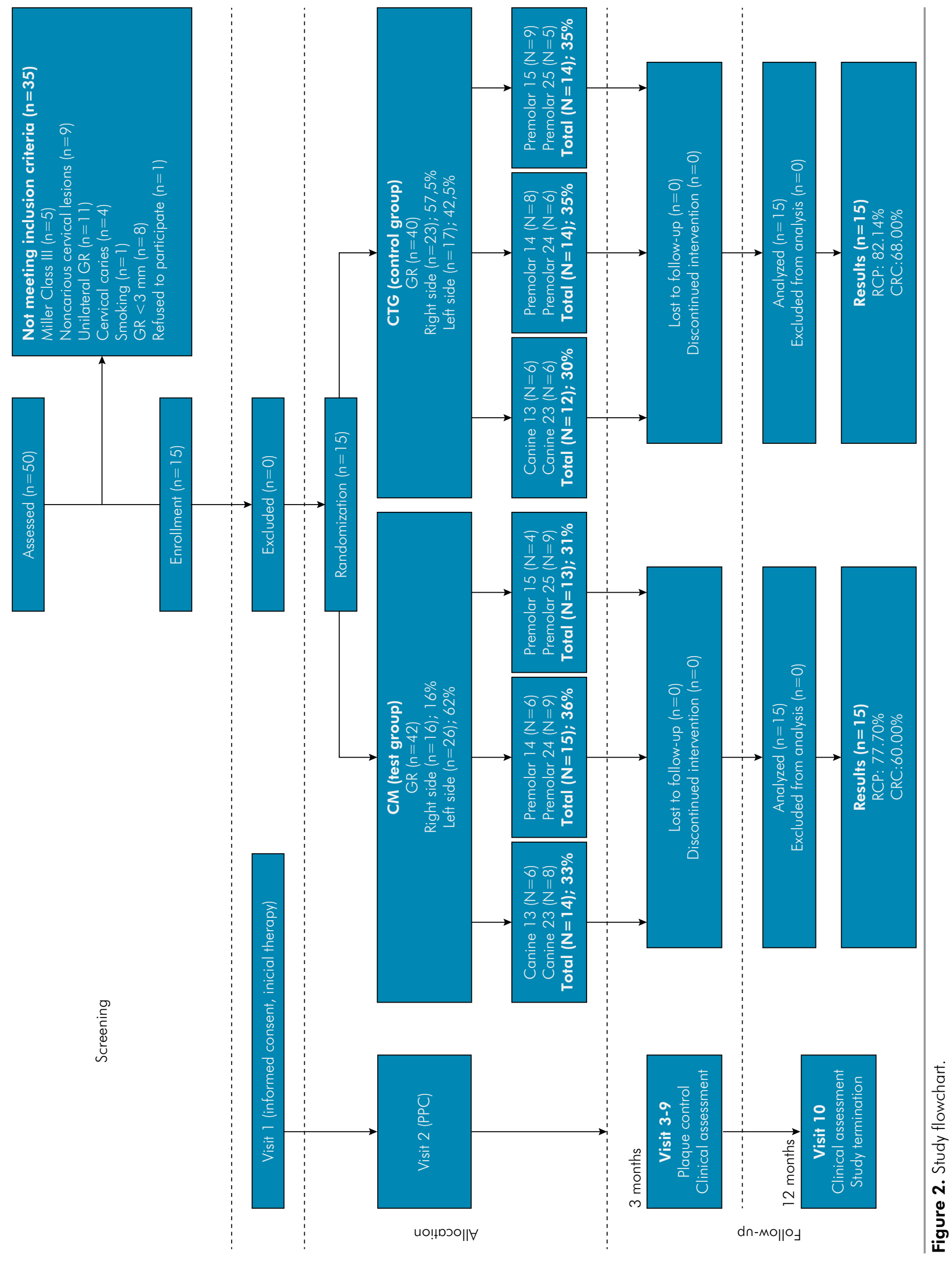


Table 1. Descriptive analysis of tooth-related variables and a comparison of the groups at baseline.

\begin{tabular}{lccc}
\hline \multirow{2}{*}{ Variable } & Control group (CTG -40 teeth) & Test group (CM - 42 teeth) Mean \pm SD & $*$ \\
\cline { 2 - 3 } & Mean \pm SD & Mean \pm SD & \\
\hline GRD* & $2.8 \pm 1.1$ & $2.7 \pm 1.1$ & 0.870 \\
CAL* & $4.0 \pm 1.2$ & $3.8 \pm 1.1$ & 0.703 \\
PD* $^{*}$ & $1.3 \pm 0.4$ & $1.1 \pm 0.4$ & 0.657 \\
KTW $^{*}$ & $2.1 \pm 1.0$ & $2.2 \pm 1.0$ & 0.715 \\
DH $^{*}$ & $4.1 \pm 3.3$ & $4.0 \pm 3.1$ & 0.833 \\
\hline
\end{tabular}

${ }^{*}$ p-values were obtained using Poisson multilevel regression. ${ }^{* *}$-values were obtained using multilevel linear regression. CTG: connective tissue graft; CM: collagen matrix; GRD: gingival recession depth; CAL: clinical attachment level; PD: probing depth; KTW: keratinized tissue width; $\mathrm{DH}$ : dentine hypersensitivity

after 12 months of follow-up. The present study demonstrated that both techniques were able to reduce GRD over 12 months with no significant difference between groups. These results are similar to those that Aroca et al. ${ }^{24}$ demonstrated using a split-mouth experimental design and a modified tunnel flap. Similarly, Cardaropoli et al. ${ }^{11}$ showed a mean GRD of $0.2 \pm 0.34 \mathrm{~mm}$ in the CM after 12 months of treatment for multiple GR. In addition, the recent multicenter trial by Tonetti et al. ${ }^{16}$ demonstrated a mean GR reduction in the treatment of multiple GR in the CM+CAF of $1.7 \mathrm{~mm}$ in 6 months. Similar to these results, the mean GR reduction in the $\mathrm{CM}$ group in the present study was $2.0 \mathrm{~mm}$. This slightly different finding may be related to differences in the study design, inclusion/exclusion criteria, and follow-up periods.

In our study, the choice of a randomized clinical trial with split-mouth design was based on a) the expectation that the difference in efficiency between CM and CTG would be clinically irrelevant in relation to $\mathrm{RC}$ and $\mathrm{b}$ ) that $\mathrm{CM}$ would offer additional advantages, compared to CTG, in terms of postoperative pain/discomfort. This study showed similar results between CM and CTG in relation to the primary outcome after 12 months. On the other hand, a large multicenter study failed to support the non-inferiority of $\mathrm{CM}$ compared to CTG in the treatment of multiple GRs, in terms of root coverage after 6 months. ${ }^{16}$ This may be explained - at least partially - by differences is sample sizes, study design (parallel versus split-mouth), number of centers (14 versus 1), surgical protocol (rotated papillae flap or trapezoidal flap designs with or without vertical releasing incisions versus rotated papillae flap), follow-up (6 months vs 12 months), different inclusion/exclusion criteria, some secondary characteristics (i.e. recession width, amount of keratinized tissue, periodontal biotype, papilla volume, flap thickness, vestibule depth, bone dehiscence dimension), and defect morphology.

The split-mouth design of our study allowed inter-individual variables to be minimized, increasing the power of the study. ${ }^{29}$ Likewise, the split-mouth study design enabled an individual analysis of patient-related subjective data (VAS score) and a better comparison of pain and esthetics between surgical treatments. Despite split-mouth design limitations, statistically significant differences in patient-related secondary outcomes (pain and esthetics) were detected in 12 months. Thus, CM demonstrated to be as good as CTG regarding RC and offered the additional benefit of causing less post-operative pain and therefore, some clinically relevant conclusions can be drawn, and these results may serve as a basis for future studies.

The mean RC was $82.14 \%$ for the CTG group and $77.7 \%$ for the teeth treated with CM. These data are consistent with the results of Hofmänner et al. ${ }^{6}$ systematic review, in which the mean RC of multiple GR ranged from $80.7 \%$ to $96.7 \%$. Likewise, Graziani et al. ${ }^{5}$ demonstrated a mean RC of $80 \%$ for the evaluated techniques. The present data revealed that CRC occurred in $68 \%$ of the sites treated in the control group and $60 \%$ in the test group, with no significant difference between groups at 12 months. Aroca et al. ${ }^{24}$ demonstrated a CRC percentage of $85 \%$ for GR treated with CTG and $42 \%$ for those treated with $\mathrm{CM}$ after tunneling. CAF alone was compared with CM under a flap in a randomized trial about the treatment of multiple GRs. ${ }^{11}$ This study found CRC in $72 \%$ of the sites treated with 
Treatment of multiple recessions with collagen matrix versus connective tissue: a randomized clinical trial

Table 2. Descriptive analysis of the primary clinical outcome (GRD), reduction in GRD, percentage and number of teeth with CRC, and secondary variables 3,6 , and 12 months after surgery.

\begin{tabular}{|c|c|c|c|}
\hline \multirow{2}{*}{ Variable } & Control group (CTG - 40 teeth) & Test group (CM - 42 teeth) & \multirow{2}{*}{$p$-value* } \\
\hline & Mean \pm SD & Mean \pm SD & \\
\hline \multicolumn{4}{|l|}{ CAL } \\
\hline Baseline & $4.0 \pm 1.2 \mathbf{A a}$ & $3.8 \pm 1.1 \mathbf{A a}$ & $0.352^{*}$ \\
\hline 3 months & $2.1 \pm 0.9 \mathbf{A b}$ & $2.1 \pm 1.2 \mathbf{A b}$ & $0.467^{*}$ \\
\hline 6 months & $2.0 \pm 0.9 \mathbf{A b}$ & $1.8 \pm 1.1 \mathbf{A b}$ & $0.354^{*}$ \\
\hline 12 months & $2.2 \pm 1.2 \mathbf{A b}$ & $1.9 \pm 1.0 \mathbf{A b}$ & $0.190^{*}$ \\
\hline \multicolumn{4}{|l|}{ CAL gain } \\
\hline 3 months & $1.9 \pm 1.1 \mathbf{A a}$ & $1.8 \pm 1.3 \mathbf{A a}$ & $0.646^{*}$ \\
\hline 6 months & $2.1 \pm 1.1 \mathbf{A a}$ & $2.0 \pm 1.3 \mathbf{A a}$ & $0.598^{*}$ \\
\hline 12 months & $1.9 \pm 1.4 \mathbf{A a}$ & $2.0 \pm 1.4 \mathbf{A a}$ & $0.642^{*}$ \\
\hline \multicolumn{4}{|l|}{ PD } \\
\hline Baseline & $1.3 \pm 0.4 \mathbf{A a}$ & $1.1 \pm 0.4 \mathbf{A a}$ & $0.329^{*}$ \\
\hline 3 months & $1.7 \pm 0.5 \mathbf{A a}$ & $1.2 \pm 0.4 \mathbf{A a}$ & $0.959^{*}$ \\
\hline 6 months & $1.7 \pm 0.5 \mathbf{A a}$ & $1.2 \pm 0.4 \mathbf{A a}$ & $0.966^{*}$ \\
\hline 12 months & $1.8 \pm 0.5 \mathbf{A a}$ & $1.2 \pm 0.4 \mathbf{A a}$ & $0.977^{*}$ \\
\hline \multicolumn{4}{|l|}{ KTW } \\
\hline Baseline & $2.1 \pm 1.0 \mathbf{A a}$ & $2.2 \pm 1.0 \mathbf{A a}$ & $0.643^{*}$ \\
\hline 3 months & $3.2 \pm 1.5 \mathbf{A b}$ & $2.6 \pm 0.9 \mathbf{A b}$ & $0.057^{*}$ \\
\hline 6 months & $3.3 \pm 1.1 \mathbf{A b}$ & $2.5 \pm 0.8 \mathbf{B b}$ & $0.031^{*}$ \\
\hline 12 months & $3.2 \pm 1.1 \mathbf{A b}$ & $2.5 \pm 0.7 \mathbf{B b}$ & $0.022^{*}$ \\
\hline \multicolumn{4}{|l|}{ KTW gain } \\
\hline 3 months & $1.2 \pm 1.3 \mathbf{A a}$ & $0.4 \pm 0.9 \mathbf{B a}$ & $0.029^{* *}$ \\
\hline 6 months & $1.2 \pm 1.0 \mathbf{A a}$ & $0.4 \pm 1.0 \mathrm{Ba}$ & $<0.001^{* *}$ \\
\hline 12 months & $1.2 \pm 1.1 \mathrm{Aa}$ & $0.3 \pm 0.7 \mathrm{Ba}$ & $<0.001^{* *}$ \\
\hline \multicolumn{4}{|l|}{ GRD } \\
\hline Baseline & $2.8 \pm 1.1 \mathbf{A a}$ & $2.7 \pm 1.1 \mathbf{A a}$ & 0.565 \\
\hline 3 months & $0.4 \pm 0.6 \mathbf{A b}$ & $0.9 \pm 1.0 \mathbf{B b}$ & 0.009 \\
\hline 6 months & $0.3 \pm 0.6 \mathbf{A b}$ & $0.6 \pm 1.0 \mathbf{B b}$ & 0.008 \\
\hline 12 months & $0.5 \pm 0.9 \mathbf{A b}(\mathbf{8 2}, \mathbf{1 4} \%)$ & $0.6 \pm 1.0 \mathbf{A b}(\mathbf{7 7 , 7 8 \% )}$ & 0.225 \\
\hline \multicolumn{4}{|l|}{ GRD reduction } \\
\hline 3 months & $2.3 \pm 0.9 \mathbf{A a}$ & $1.9 \pm 1.2 \mathbf{A a}$ & 0.072 \\
\hline 6 months & $2.5 \pm 1.0 \mathbf{A a}$ & $2.0 \pm 1.2 \mathbf{A a}$ & 0.099 \\
\hline 12 months & $2.2 \pm 1.2 \mathbf{A a}$ & $2.0 \pm 1.2 \mathbf{A a}$ & 0.233 \\
\hline \multicolumn{4}{|c|}{ Number of teeth with CRC (\%) } \\
\hline 3_months & & & 0.115 \\
\hline No & 14 (35\%) & $23(55 \%)$ & \\
\hline Yes & $26(65 \%)$ & $19(45 \%)$ & \\
\hline 6_months & & & 0.134 \\
\hline No & $8(20 \%)$ & $17(40.5 \%)$ & \\
\hline Yes & $32(80 \%)$ & $25(59.5 \%)$ & \\
\hline 12 months & & & 0.374 \\
\hline No & $13(32 \%)$ & 17 (40\%) & \\
\hline Yes & 27 (68\%) & $25(60 \%)$ & \\
\hline
\end{tabular}

*One-tailed $\mathrm{p}$ value calculated using Poisson multilevel regression. ${ }^{* *}$ One-tailed $\mathrm{p}$ value obtained using multilevel linear regression. Different lowercase letters in columns indicate significant differences between evaluation times $(p<0.05)$. Different uppercase letters in rows indicate significant differences between groups. CTG: connective tissue graft; CM; collagen matrix; CAL: clinical attachment level; PD: probing depth; KTW: keratinized tissue width; GRD: gingival recession depth; CRC: complete root coverage. 
Table 3. Descriptive analysis of patient evaluation: $\mathrm{DH}$ and pain a comparison between groups.

\begin{tabular}{|c|c|c|c|}
\hline \multirow{2}{*}{ Variable } & Control group (CTG) & Test group (CM) Mean \pm SD & $\mathrm{p}$-value \\
\hline & Mean \pm SD & Mean \pm SD & \\
\hline \multicolumn{4}{|c|}{ Patient evaluation VAS ( $0=$ without pain and $10=$ worst pain possible $)$} \\
\hline \multicolumn{4}{|l|}{$\mathrm{DH}$} \\
\hline Baseline & $4.1 \pm 3.3 \mathbf{A}$ & $4.0 \pm 3.1 \mathbf{A}$ & $0.833^{*}$ \\
\hline \multicolumn{4}{|l|}{ DH reduction } \\
\hline 3_months & $0.8 \pm 3.7 \mathbf{A a}$ & $1.5 \pm 3.4 \mathbf{A a}$ & $0.816^{* *}$ \\
\hline 6 months & $2.0 \pm 3.0 \mathbf{A b}$ & $2.3 \pm 3.3 \mathbf{A b}$ & $0.647^{* *}$ \\
\hline 12 months & $2.1 \pm 3.2 \mathbf{A b}$ & $2.4 \pm 3.6 \mathbf{A b}$ & $0.915^{* *}$ \\
\hline \multicolumn{4}{|l|}{ Pain $\$$} \\
\hline 8 - $h$ & $2.73 \pm 2.39 \mathbf{A a}$ & $1.34 \pm 1.63 \mathbf{B a}$ & 0.004 \\
\hline 1 day & $1.89 \pm 1.83 \mathbf{A b}$ & $1.19 \pm 1.30 \mathbf{A b}$ & 0.059 \\
\hline 7 days & $3.17 \pm 3.22 \mathbf{A c}$ & $0.75 \pm 0.89 \mathbf{B c}$ & 0.003 \\
\hline 15 days & $1.50 \pm 2.40 \mathbf{A d}$ & $0.22 \pm 0.3 \mathbf{B d}$ & 0.034 \\
\hline 30 days & $0.32 \pm 1.05 \mathbf{A e}$ & $0.08 \pm 0.26 \mathbf{A e}$ & 0.374 \\
\hline 90 days ${ }^{* * *}$ & $0.00 \pm 0.00$ & $0.00 \pm 0.00$ & - \\
\hline 180 days ${ }^{* * *}$ & $0.00 \pm 0.00$ & $0.00 \pm 0.00$ & - \\
\hline 365 days ${ }^{* * *}$ & $0.00 \pm 0.00$ & $0.00 \pm 0.00$ & - \\
\hline
\end{tabular}

${ }^{*} p$-values obtained using multilevel linear regression; ${ }^{* *}$ One-tailed $p$ value obtained using multilevel linear regression. Different uppercase letters in rows indicate significant differences between groups, irrespective of evaluation time, obtained using multilevel linear regression ( $p=0.001)$ Different lowercase letters in columns indicate significant differences between time-points, irrespective of group $(p<0.001)$. ${ }^{* * *}$ Excluded from the analysis because of the absence of pain in all participants. CTG: connective tissue graft; CM: collagen matrix; VAS: visual analogic scale.

$\mathrm{CM}+\mathrm{CAF}$ and in $58 \%$ of the sites treated with $\mathrm{CAF}$ alone. On the other hand, a recent randomized controlled multicenter international trial, ${ }^{16}$ which compared $\mathrm{CAF}+\mathrm{CM}$ with $\mathrm{CAF}+\mathrm{CTG}$ for the treatment

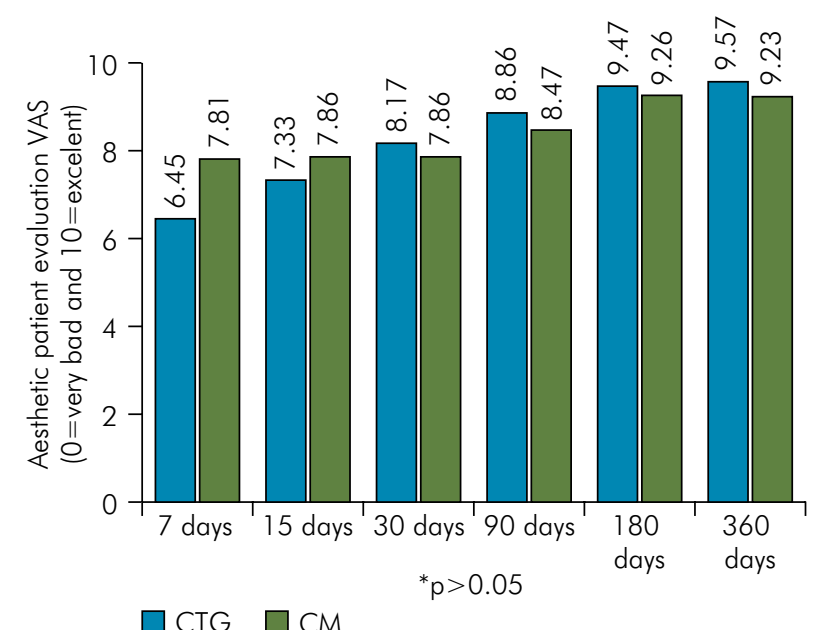

${ }^{*}$ p-values were obtained using multilevel linear regression and indicated no significant differences between groups and times $\left({ }^{*} p=0.637\right)$. CTG: connective tissue graft; CM: collagen matrix; VAS: visual analogic scale.

Figure 3. Aesthetic patient evaluation VAS $(0=$ very bad and $10=$ excelente). of multiple GRs, found CRC in $70 \%$ of sites treated with CAF+CTG and in only $48 \%$ of sites treated with $\mathrm{CAF}+\mathrm{CM}$. Odds ratios of CRC at 6 months were significantly higher for CTG than CM-treated cases. ${ }^{16}$

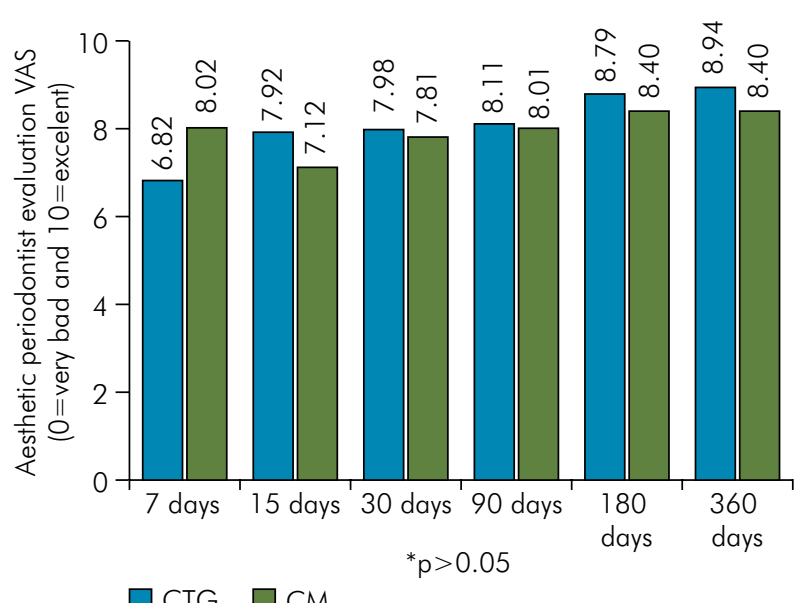

${ }^{*} p$-values were obtained using multilevel linear regression and indicated no significant differences between groups and times $\left({ }^{*} p=0.834\right)$. CTG: connective tissue graft; $C M$ : collagen matrix; VAS: visual analogic scale.

Figure 4. Aesthetic periodontist evaluation VAS $(0=$ very bad and $10=$ excelente). 
These differences may be related to differences in the surgical technique, anatomical factors, GRD at baseline, follow-up time, surgeon experience, type of study design, ${ }^{5}$ and choice of statistical test used to evaluate multiple sites. ${ }^{24}$

The present investigation demonstrated that both procedures resulted in significant increases in KTW at 12 months compared with baseline. The mean gain was higher in the control group $(1.2 \pm 1.1 \mathrm{~mm})$ than in the test group $(0.3 \pm 0.7 \mathrm{~mm})$. Unlike this study, Jepsen et al. ${ }^{13}$ observed an increase in KTW of $0.93 \mathrm{~mm}$ for CM over the same period. Similarly, a significant increase in KTW $(1.34 \mathrm{~mm})$ in the treatment of localized GR was described 12 months after treatment with CM. ${ }^{8}$ These differences in KTW may be related to the use of different evaluation methods, flap design, and follow-up times. In addition to tissue gain, the increase in KTW may be attributed to a tendency of the mucogingival junction to re-establish its original genetically determined position, which is observed after 1 year of postsurgical monitoring. ${ }^{25}$ In contrast, coronary migration of the gingival margin (creeping attachment) may vary from 0.43 to $3 \mathrm{~mm}$ (mean of $1 \mathrm{~mm}$ ) after free gingival graft, CTG, acellular dermal matrix, and crown lengthening surgeries. ${ }^{26}$ Factors affecting creeping attachment include shallow and localized GR, tooth position, oral hygiene, patient age, and gingival thickness. ${ }^{26}$ Information on this phenomenon in the treatment of multiple GR with CM is limited.

The postsurgical improvement in $\mathrm{DH}$ can be explained by the sealing of the dentine tubules resulting from increased $\mathrm{KT}^{27}$ and the CRC of the defects. ${ }^{28}$ Both treatments performed showed a significant reduction in $\mathrm{DH}$ at 12 months, with no difference between groups. CTG reduced DH by $51.2 \%$ compared with $60 \%$ for $\mathrm{CM}$. These results are similar to those of Moreira et al., ${ }^{31}$ who demonstrated a reduction of $62.5 \%$ in $\mathrm{DH}$ when using $\mathrm{CM}$ to treat localized GR. However, some patients in our study also presented DH complaints after surgery, despite pain levels being lower than those at baseline. Such results were also encountered by Clauser et al. ${ }^{28}{ }^{28}$ who associated a total reduction in $\mathrm{DH}$ with CRC of the defect. In our study, 27 of the 40 control group GR (68\%) and 25 of the 42 test group GR (60\%) had CRC.
The limited data available suggest a positive effect of RC surgery on $\mathrm{DH}^{3}$

Both procedures caused pain after 8 hours, 1 day, 7, 15, and 30 days. However, the CTG group had higher post-operative pain than the CM group after 8 hours, 7, and 15 days. Similar findings were observed by Sanz et al., ${ }^{7}$ who reported greater post-operative pain at 10 and 30 days in patients treated with free CTG to increase the KT band around teeth and implants. On the other hand, a significant difference in pain evaluated by VAS was observed only at day 7 in patients treated with CTG+CAF in the treatment of multiple GR.${ }^{16}$ Despite offering better $\mathrm{RC}$ results than other treatment modalities, CTG is often associated with increased operative time, pain, discomfort, and postoperative complications related to the surgical donor site. . $^{3,4,7,8,9,10}$ When multiple GR are treated, these factors can be exacerbated because the required amount of donor tissue is greater; consequently, this surgical approach may reduce the patient's interest and acceptance. Therefore, there are clearly measurable patient benefits deriving from the avoidance of autologous soft tissue grafting by replacing them with CM-based materials in multiple adjacent recessions. ${ }^{16}$ For these reasons, although $\mathrm{CM}$ did not produce superior results in relation to the primary and secondary clinical outcomes at 12 months, it may represent a viable alternative for the treatment of multiple GR, demonstrating additional benefits in terms of patient-related subjective parameters (post-operative pain).

At the end of this study, both surgical techniques improved esthetics according to both the patients and the periodontist, and neither evaluation yielded a significant difference between treatment groups. These results are similar to those described by McGuire and Scheyer ${ }^{8}$ after 1 year of localized GR treatment with CTG and CM. Similarly, after 5 years, the authors reported a high level of esthetic satisfaction in both groups. ${ }^{14}$

Within the limits of this evaluation, it seems that CTG presents a better potential for the treatment of recessions $>4 \mathrm{~mm}$. According to the explorative sub-analysis of deep recessions, CTG might be more indicated than CM. It can be speculated that CTG, by 
providing greater soft tissue thickness/KTH, does not really improve surgical outcomes compared to $\mathrm{CM}+\mathrm{CAF}$ but facilitates long-term patient maintenance. ${ }^{9}$ However, this finding should be interpreted with caution. There is a wide variety of opinions of what should be considered a deep recession. According to Zucchelli et al. ${ }^{9}$ the limit is $3 \mathrm{~mm}$. Conversely, Bouchard et al. ${ }^{32}$ consider deep recessions the defects $>5 \mathrm{~mm}$. In addition, the number of cases that raised such a hypothesis is very limited and further studies should address this topic. It is important to emphasize that the present study was not designed to evaluate deep recessions.

The information generated in this clinical trial contributes to clinical decision-making because multiple GR treatment is still based on the knowledge obtained from localized GR treatment and clinician experience.

\section{Conclusion}

Within the limitations of this clinical study, the results indicated that both treatments were able to promote RC after 12 months and GRD was similar in both control and test groups.

\section{Acknowledgments}

The authors acknowledge the support of Dr Hugo Roberto Lewgoy (Curaprox ${ }^{\circledR}$ CURADEN AG, Kriens, Switzerland) for supplying toothbrushes for patients and Dr Fausto Medeiros Mendes (University of São Paulo) for his support in statistical analyses.

\section{References}

1. Miller PD Jr. A classification of marginal tissue recession. Int J Periodontics Restorative Dent. 1985;5(2):8-13.

2. Cairo F, Nieri M, Pagliaro U. Efficacy of periodontal plastic surgery procedures in the treatment of localized facial gingival recessions. A systematic review. J Clin Periodontol. 2014 Apr;41(41 Suppl 15):S44-62. https://doi.org/10.1111/jcpe.12182

3. Tatakis DN, Chambrone L, Allen EP, Langer B, McGuire MK, Richardson CR, et al. Periodontal soft tissue root coverage procedures: a consensus report from the AAP Regeneration Workshop. J Periodontol. 2015 Feb;86(2 Suppl):S52-5. https://doi.org/10.1902/jop.2015.140376

4. Tonetti MS, Jepsen S. Clinical efficacy of periodontal plastic surgery procedures: Consensus Report of Group 2 of the 10th European Workshop on Periodontology. J Clin Periodontol. 2014 Apr;41Suppl 15:S36-43. https://doi.org/10.1111/icpe.12219

5. Graziani F, Gennai S, Roldán S, Discepoli N, Buti J, Madianos P, et al. Efficacy of periodontal plastic procedures in the treatment of multiple gingival recessions. J Clin Periodontol. 2014 Apr;41 Suppl 15:S63-76. https://doi.org/10.1111/jcpe.12172

6. Hofmänner P, Alessandri R, Laugisch O, Aroca S, Salvi GE, Stavropoulos A, et al. Predictability of surgical techniques used for coverage of multiple adjacent gingival recessions: a systematic review. Quintessence Int. 2012 Jul-Aug;43(7):545-54.

7. Sanz M, Lorenzo R, Aranda JJ, Martin C, Orsini M. Clinical evaluation of a new collagen matrix (Mucograft prototype) to enhance the width of keratinized tissue in patients with fixed prosthetic restorations: a randomized prospective clinical trial. J Clin Periodontol. 2009 Oct;36(10):868-76. https://doi.org/10.1111/i.1600-051X.2009.01460.x

8. McGuire MK, Scheyer ET. Xenogeneic collagen matrix with coronally advanced flap compared to connective tissue with coronally advanced flap for the treatment of dehiscence-type recession defects. J Periodontol. 2010 Aug;81(8):1108-17. https://doi.org/10.1902/jop.2010.090698

9. Zucchelli G, Marzadori M, Mounssif I, Mazzotti C, Stefanini M. Coronally advanced flap + connective tissue graft techniques for the treatment of deep gingival recession in the lower incisors. A controlled randomized clinical trial. J Clin Periodontol. 2014 Aug;41(8):806-13. https://doi.org/10.1111/icpe.12269

10. Griffin TJ, Cheung WS, Zavras Al, Damoulis PD. Postoperative complications following gingival augmentation procedures. J Periodontol. 2006 Dec;77(12):2070-9. https://doi.org/10.1902/jop.2006.050296

11. Cardaropoli D, Tamagnone L, Roffredo A, Gaveglio L. Treatment of gingival recession defects using coronally advanced flap with a porcine collagen matrix compared to coronally advanced flap with connective tissue graft: a randomized controlled clinical trial. J Periodontol. 2012 Mar;83(3):321-8. https://doi.org/10.1902/jop.2011.110215

12. Lee $\mathrm{KH}, \mathrm{Kim} \mathrm{BO}$, Jang HS. Clinical evaluation of a collagen matrix to enhance the width of keratinized gingiva around dental implants. J Periodontal Implant Sci. 2010 Apr;40(2):96-101. https://doi.org/10.5051/ipis.2010.40.2.96

13. Jepsen K, Jepsen S, Zucchelli G, Stefanini M, de Sanctis M, Baldini N, et al. Treatment of gingival recession defects with a coronally advanced flap and a xenogeneic collagen matrix: a multicenter randomized clinical trial. J Clin Periodontol. 2013 Jan;40(1):82-9. https://doi.org/10.1111/icpe.12019 
Treatment of multiple recessions with collagen matrix versus connective tissue: a randomized clinical trial

14. McGuire MK, ScheyerET. Long-term results comparing xenogeneic collagen matrix and autogenous connective tissue grafts with coronally advanced flaps for treatment of dehiscence-type recession defects. J Periodontol. 2016 Mar;87(3):221-7. https://doi.org/10.1902/jop.2015.150386

15. Cardaropoli D, Tamagnone L, Roffredo A, Gaveglio L. Coronally advanced flap with and without a xenogenic collagen matrix in the treatment of multiple recessions: a randomized controlled clinical study. Int J Periodontics Restorative Dent. 2014;34 Suppl 3:s97-102. https://doi.org/10.11607/prd.1605

16. Tonetti MS, Cortellini P, Pellegrini G, Nieri M, Bonaccini D, Allegri M, et al. Xenogenic collagen matrix or autologous connective tissue graft as adjunct to coronally advanced flaps for coverage of multiple adjacent gingival recession: randomized trial assessing non-inferiority in root coverage and superiority in oral health-related quality of life. J Clin Periodontol. 2018 Jan;45(1):78-88. https://doi.org/10.1111/icpe.12834

17. Stefanini M, Jepsen K, Sanctis M, Baldini N, Greven B, Heinz B, et al. Patient-reported outcomes and aesthetic evaluation of root coverage procedures: a 12-month follow-up of a randomized controlled clinical trial. J Clin Periodontol. 2016 Dec;43(12):1132-41. https://doi.org/10.1111/jcpe.12626

18. Moher D, Hopewell S, Schulz KF, Montori V, Gøtzsche PC, Devereaux PJ, et al. CONSORT 2010 explanation and elaboration: updated guidelines for reporting parallel group randomised trials. BMJ. 2010 Mar;340 mar23 1:c869. https://doi.org/10.1136/bmi.c869

19. Zucchelli G, De Sanctis M. Treatment of multiple recession-type defects in patients with esthetic demands. J Periodontol. 2000 Sep;71(9):150614. https://doi.org/10.1902/jop.2000.71.9.1506

20. Harris RJ. The connective tissue and partial thickness double pedicle graft: a predictable method of obtaining root coverage. J Periodontol. 1992 May;63(5):477-86. https://doi.org/10.1902/jop.1992.63.5.477

21. Ainamo J, Bay I. Problems and proposals for recording gingivitis and plaque. Int Dent J. 1975 Dec;25(4):229-35.

22. Cortellini P, Tonetti M, Baldi C, Francetti L, Rasperini G, Rotundo R, et al. Does placement of a connective tissue graft improve the outcomes of coronally advanced flap for coverage of single gingival recessions in upper anterior teeth? A multi-centre, randomized, double-blind, clinical trial. J Clin Periodontol. 2009 Jan;36(1):68-79. https://doi.org/10.1111/i.1600-051X.2008.01346.x

23. Gernhardt CR. How valid and applicable are current diagnostic criteria and assessment methods for dentin hypersensitivity? An overview. Clin Oral Investig. 2013 Mar;17(17 Suppl 1):S31-40. https://doi.org/10.1007/s00784-012-0891-1

24. Aroca S, Molnár B, Windisch P, Gera I, Salvi GE, Nikolidakis D, et al. Treatment of multiple adjacent Miller class I and II gingival recessions with a Modified Coronally Advanced Tunnel (MCAT) technique and a collagen matrix or palatal connective tissue graft: a randomized, controlled clinical trial. J Clin Periodontol. 2013 Jul;40(7):713-20. https://doi.org/10.1111/icpe.12112

25. Zucchelli G, Mele M, Mazzotti C, Marzadori M, Montebugnoli L, De Sanctis M. Coronally advanced flap with and without vertical releasing incisions for the treatment of multiple gingival recessions: a comparative controlled randomized clinical trial. J Periodontol. 2009 Jul;80(7):1083-94. https://doi.org/10.1902/jop.2009.090041

26. Hwang D, Wang HL. Flap thickness as a predictor of root coverage: a systematic review. J Periodontol. 2006 Oct;77(10):1625-34. https://doi.org/10.1902/jop.2006.060107

27. Douglas de Oliveira DW, Marques DP, Aguiar-Cantuária IC, Flecha OD, Gonçalves PF. Effect of surgical defect coverage on cervical dentin hypersensitivity and quality of life. J Periodontol. 2013 Jun;84(6):768-75. https://doi.org/10.1902/jop.2012.120479

28. Clauser C, Nieri M, Franceschi D, Pagliaro U, Pini-Prato G. Evidence-based mucogingival therapy. Part 2: ordinary and individual patient data meta-analyses of surgical treatment of recession using complete root coverage as the outcome variable. J Periodontol. 2003 May;74(5):74156. https://doi.org/10.1902/jop.2003.74.5.741

29. Smaïl-Faugeron V, Fron-Chabouis H, Courson F, Durieux P. Comparison of intervention effects in split-mouth and parallel-arm randomized controlled trials: a meta-epidemiological study. BMC Med Res Methodol. 2014 May;14(1):64. https://doi.org/10.1186/1471-2288-14-64

30. Zucchelli G, Mounssif I, Mazzotti C, Stefanini M, Marzadori M, Petracci E, et al. Coronally advanced flap with and without connective tissue graft for the treatment of multiple gingival recessions: a comparative short- and long-term controlled randomized clinical trial. J Clin Periodontol. 2014 Apr;41(4):396-403. https://doi.org/10.1111/jcpe.12224

31. Moreira AR, Santamaria MP, Silvério KG, Casati MZ, Nociti Junior FH, Sculean A, et al. Coronally advanced flap with or without porcine collagen matrix for root coverage: a randomized clinical trial. Clin Oral Investig. 2016 Dec;20(9):2539-49. https://doi.org/10.1007/s00784-016-1757-8

32. Bouchard P, Malet J, Borghetti A. Decision-making in aesthetics: root coverage revisited. Periodontol 2000. 2001;27(1):97-120. https://doi.org/10.1034/i.1600-0757.2001.027001097.x 